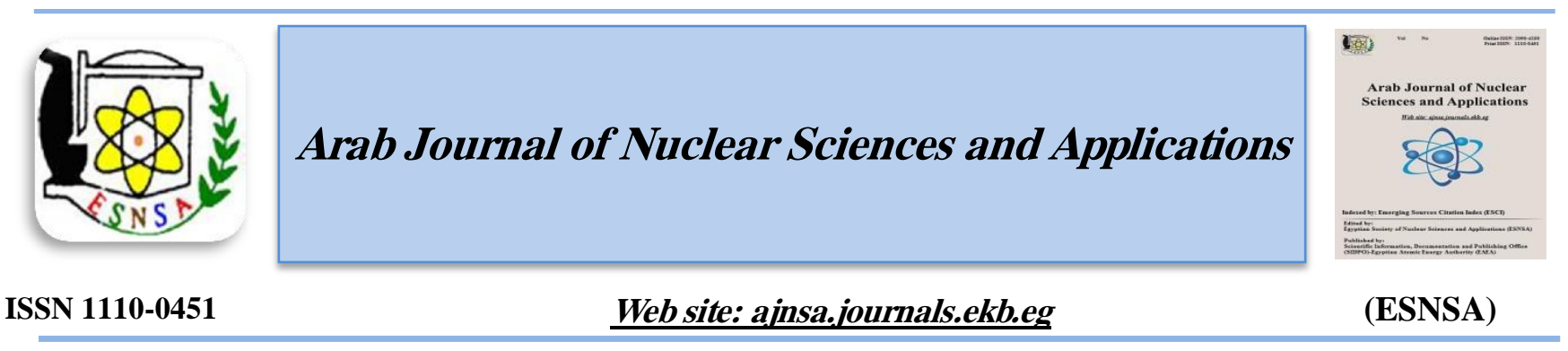

\title{
Adsorption Studies of Zn (II) onto Nano Biomaterials from Aqueous Media
}

\author{
Amany T.Kassem ${ }^{1 *}$ and Salah A.Wanees ${ }^{1}$ \\ "Hot Laboratories Center, Atomic Energy Authority, Cairo, Egypt, \\ ${ }^{I}$ Faculty of Science, Zagazig University, Zagazig, Egypt
}

Received 22 ${ }^{\text {th }}$ Aug. 2018 Hydroxyapatite and $\beta$-tricalcium phosphate as porous composites were prepared by a sol-gel process. Accepted $26^{\text {th }}$ Jun. 2019 We gota solid powder form composites as small particles. Mixed powder by ultrasonically dispersed throughout the aqueous solution containing an optimum amount of Ring-opening- polymerization was used for a poly (d, l-lactide-co-glycolide) acid polymeric gel as an appropriate functional system for solid-phase extraction of metal ions from aqueous medium. The zinc ions adsorption with polylatic-coglycolic)acid (PLGA) as original technique for scaffolds where, the cations adsorption zinc(II) and Co(II) with PLGA-polymer opening ring is considered eco-friendly alternative technology for water treatment. However, the application of PLGA to zinc (II) adsorption is limited, due to its lower surface area and porosity. Then, the prepared a PLGA scaffold with a huge structure was used as an alternative absorbent material to remove zinc ion and cobalt from nitrate solutions. Characterization of structure and analysis of spectral of the most important features of PLGA scaffold and carried out. The PLGA scaffold offered pore sizes from $100-200 \mu \mathrm{m}$. Porosity up to $95.4 \%$ and the specific surface area of PLGA $81 \pm 2.4 \mathrm{~m}^{2} \mathrm{~g}^{-1-}(\mathrm{SEM})$; moreover, the adsorption of isotherm was applied by the models Langmuir and Freundlich, the adsorption of metal ions can explain the effect of composites recycle on the adsorption of two models, fitting of zinc and cobalt ions adsorption of correlation coefficient the Langmuir model is the best than Freundlich model.

Keywords: Hydroxyapatite; $\beta$ - TCP; PLGA scaffolds; $\mathrm{Zn}\left(\mathrm{NO}_{3}\right)_{2} \cdot 6 \mathrm{H}_{2} \mathrm{O}$; Co $\left(\mathrm{NO}_{3}\right)_{2} \cdot 6 \mathrm{H}_{2} \mathrm{O}$; Adsorption; Langmuir and Freundlich models

\section{Introduction}

Hydroxyapatite $\left[\mathrm{Ca}_{10}\left(\mathrm{PO}_{4}\right)_{6}(\mathrm{OH})_{2}\right]$ and betaTricalcium phosphate $\left[\mathrm{Ca}_{3}\left(\mathrm{PO}_{4}\right)_{2}\right]$ ceramics are bio-compatible materials that offer a chemical environment and a surface conducive to new bone formation. Now day's unique techniques have been evolved to comprehend hydroxyapatite/Poly caprolactone composites by means of bodily blending [1].

Sol-gel methods have attracted a whole lot attention [2]. Because of the well-recognized inherent benefits of technique to generate glass, glass-ceramic and ceramics powders; these consist of: homogeneous molecular mixing, low processing temperature, the potential to generate nano-sized debris, bulk amorphous and skinny films. Natural-inorganic hybrid composite materials put together through the sol-gel process are very promising materials [3].

The sol-gel strategies studied up to now but have some shortcomings, most drastically, the use of both expensive alkoxide-based precursors or the want for numerous complex steps to make certain whole dissolution of precursors to generate phase pure HAP.

Nanoparticles (Nano powders, nanocrystals, or nano structured particles) are microscopic particles with at least one dimension in the nanometer scale (usually, $100 \mathrm{~nm}$ or less). In general, nanoparticles offer improved properties compared with conventional-sized materials because of their large surface-to-volume ratio (specific surface area)

Corresponding author: amany.kassem@ymail.com

DOI: 10.21608/ajnsa.2019.4896.1113

(C) Scientific Information, Documentation and Publishing Office (SIDPO)-EAEA 
[4,5]. To control the properties of HAp nanoparticles, it is important to control the particle morphology, which can be achieved by adjusting their synthesis methods. Modification of HAp is also important for the regulation of its physiochemical properties. ROP of cyclic dimers has been examined to get high molecular mass and having specific micro structured polymers for biomedical applications using various metal initiators, organo metal complexes and metal free initiator systems. Heavy metal catalysts (Co, Zn, $\mathrm{Pb}, \mathrm{Zr}, \mathrm{Bi}$ and $\mathrm{Y}$ ) are not recommended for biomedical applications. zinc (II) is frequently found in effluents discharged from industries, such as electroplating, pigments, battery manufacturing units, mining, metallurgy and municipal wastewater treatment plants. zinc (II) is a wellknown toxic metal ion $[6,7]$. The removal of zinc (II) ions from wastewater includes precipitation, coagulation, ion exchange, membrane filtration, and electrolysis [8-16].

In this work, the Sorption experiments of Co (II) and $\mathrm{Zn}$ (II) ions in nitrate medium on nano-apatite with addition of poly (d, 1-lactide-co-glycolide Acid (PLGA) as matrix composites to constitute polymer composites scaffold as surface modified materials. The effect of adsorption isotherm for applying Langmuir and Freundlich models was studied.

\section{Experimental \\ Reagents and Instruments}

Hydroxyapatite as a natural bone from animals, $\beta$ Tricalcium phosphate as prepared from natural bone underwent a calcination process at different temperatures. Then, they were washed from ethanol and water deionized, dried in the microwave at $50^{\circ} \mathrm{C}$, and a white powder from nano- $\left[\mathrm{PO}_{4}\right]^{-3}$ was obtained. The structure of PLGA (polymer) was purchased from Sigma-Aldrich, nDodecane (Merck with a purity of over 99\%). Concentrations of polymer and nano-biomaterials were determined using Atomic Absorption spectrophotometer. Model 210 VGP, USA, pH measured by CG-820 Schott Gerate $\mathrm{pH}$-meter. The heavy metal cations such as Co (II) and $\mathrm{Zn}$ (II) were obtained from Merck-as analytical grade, prepared stock solution in $\mathrm{HNO}_{3}$, yield $\mathrm{Zn}\left(\mathrm{NO}_{3}\right)_{2} \cdot 6 \mathrm{H}_{2} \mathrm{O}$ and $\mathrm{Co}\left(\mathrm{NO}_{3}\right)_{2} \cdot 6 \mathrm{H}_{2} \mathrm{O}$ has been put in deionized water and adjusted $\mathrm{pH}$-meter by diluted sodium hydroxide and $0.1 \mathrm{M} \mathrm{HCl}$.

\section{Preparation of nHAP- $\beta$-TCP and nHAP/PLGA- $\beta$-TCP}

One g/L Hydroxyapatite, $\mathrm{Ca}_{10}\left(\mathrm{PO}_{4}\right)_{6}(\mathrm{OH})_{2}$ which has a solubility constant at $2.34 .4 \times 10^{-59} \mathrm{~mol} \mathrm{dm}^{-3}$ powder for calcium phosphate was dissolved in $100 \mathrm{~cm}^{3}$ of $\mathrm{H}_{2} \mathrm{O}$. Then it was mixed with the nHAP solution, and the mixture was stirred for $20 \mathrm{~min}$ at $60-80^{\circ} \mathrm{C}$. Then, nHAP-n- $\beta-\mathrm{TCP}$ was obtained by co-precipitation of the mixture of the nanocomposites and the zinc ions compounds in the presence in nitrate medium solution and the final $\mathrm{pH}$ of the solution was $10.06 \pm 0.03$ after coprecipitation. In Addition, the prepared nano sphere composites were suspended in aqueous solution for crosslinking, and left standing for 4$4.5 \mathrm{~h}$ at $25^{\circ} \mathrm{C}$ under continuous stirring. The ultimate, product was washed by distilled water for several times until $\mathrm{pH}$ reached to stable state, and stored for further applications. nHAP/PLGA- $\beta$ TCP was synthesized approximately by the same method as nHAP- $\beta$-TCP. Except for the addition of PLGA. In the mixture of nano-composites and the zinc, cobalt salts, $0.5 \mathrm{~g}$ PLGA powder was added under strong stirring Fig. (1a). The PLGA blended nano sphere composites were obtained by the same co-precipitation technique. Subsequently, the nano sphere composites were crosslinked as usual. Thereafter, the finished products were washed and stored for further applications.<smiles>CC1OC(=O)C(C)C(=O)O1</smiles>

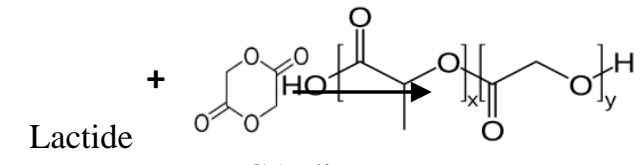

glycolide PLGA-dimer

Fig. (1a): Preparation of Poly Lactic-co-Glycolic Acid (dimer)

\section{Preparation of $\beta$-Tri calcium phosphate by Sol- gel technique}

Synthesized calcium phosphate powders by ethanol Based sol-gel method, phosphorus pentoxide $\left(\mathrm{P}_{2} \mathrm{O}_{5}\right.$, MERCK Co. $)$ and $(\mathrm{Ca}$ $\left(\mathrm{NO}_{3}\right)_{2} \cdot 4 \mathrm{H}_{2} \mathrm{O}$, Sigma-Aldrich MERCK Co) were utilized, as chemical progenitors, for $\mathrm{Ca} / \mathrm{P}$, respectively. Aqueous solutions of both phosphorus pentoxide $0.5 \mathrm{M}$ and calcium nitrate 1.5 $\mathrm{M}$ in pure ethanol $99 \%$ were prepared separately. Then, the $\mathrm{P}_{2} \mathrm{O}_{5}$ solution was slowly poured into the solution containing $\left.\mathrm{CaNO}_{3}\right)_{2} \cdot 4 \mathrm{H}_{2} \mathrm{O}$ which was stirred vigorously with mechanical stirrer (1200-1450 rpm). As a result of sol stirring for 15-20 min. the gel was obtained, through the 
process of longevity, the resulted transparent sol was kept in a closed container for $36 \mathrm{~h}$ at $25^{\circ} \mathrm{C}$. After drying in furnace with $100-120^{\circ} \mathrm{C}$, the resulted powders were calcined at $900{ }^{\circ} \mathrm{C}$ for $8 \mathrm{~h}$ [17].

\section{Characterization of nHAP- $\beta-T C P$ and nHAP/PLGA- $\beta$-TCP}

Poly (Lactic-co-glycolic) acid was coated by $\beta$ tricalcium phosphate as scaffold. of The morphology and structure of the scaffold were studied using scanning electron microscope (JEOL (JSM-5500 LV) in the Regional Center of Mycology, Al-Azhar University, Cairo, Egypt. Determination of pore size of $\beta$-TCP, HAP and PLGA scaffolds before and after coating by $\beta$-TCP and HAP was carried out using Quantachrome Nova 1000 E, USA. The pore sizes of $\beta$-TCP $2.86 \mu \mathrm{m}$ strengths reached $0.4 \mathrm{MPa}$, PLGA $6.80 \pm 1.34 \mu \mathrm{m}$ and pore size of nHAP was $80 \mu \mathrm{m}$ respectively [17].

The FTIR spectra of nHAP, $\beta$-HAP and PLGA/ $n$ Dodecane, were recorded using a Fourier transform infrared spectrometer (Spectrum BX 11, Perkin Elmer Model). Total samples were prepared as the range of the scanning wave numbers was $400-4000 \mathrm{~cm}^{-1}$.

\section{Adsorption methods}

Adsorption of $0.14 \mathrm{ppm}$ from $\mathrm{Zn}$ (II) and Co (II) in $50 \mathrm{ml}$ agitation for 30 minutes after removal of $\mathrm{Zn}$ (II) from $\mathrm{HNO}_{3}$ aqueous solution, the concentration of heavy metals can be determination by ICP-MS. The equalization of adsorption, $\mathrm{q}\left(\mathrm{mg} \mathrm{g}^{-1}\right)$, was calculated according to the following equation (1):

$q=\frac{C_{0}-C_{e}}{w} x V$

Where $\mathrm{C}_{0}$ and $\mathrm{C}_{\mathrm{e}}\left(\mathrm{mg} \mathrm{dm}^{-3}\right)$ are the initial and final $\mathrm{Zn}$ (II), $\mathrm{Co}$ (II) concentrations, $\mathrm{V}$ is the volume of the $\mathrm{Zn}(\mathrm{II})$ and $\mathrm{Co}(\mathrm{II})$ ions solution $\left(\mathrm{dm}^{3}\right)$, and $\mathrm{m}$ is the weight of the PLGA ( $g$ ) in the dried adsorbents.

\section{Study of batch uptake\%}

The ion exchange PLGA-composites of $\mathrm{Zn}$ (II) and Co (II) ions on polymeric ring opening as modified was accomplished using the batch process [18-22]. The batch adsorption experiments were proceed using $100 \mathrm{mg}$ of adsorbent of desired concentrations at room temperature, shaken of the bottles in a sieve for $2 \mathrm{~h}$, the solutions containing zinc and cobalt ions were separated after precipitation ratio $\left(\mathrm{K}_{\mathrm{d}}\right)$ calculated by equation (2) and equal the distribution ratios of zinc ions $=199.7$ $\mathrm{ml} / \mathrm{g}$ and cobalt ions $=168 \mathrm{ml} / \mathrm{g}$ respectively and show the figure.4.

$D=K_{d}\left(1+K_{a}\right) /\left[H^{+}\right]$

\section{Recycling and desorption procedures \\ Recycling techniques $(R \& D)$}

Utilizing of the nano-composites nHAP$\beta T C P / P L G A$ is advantageous when repeating adsorption-desorption procedure. After the first batch reaction of nano-calcium phosphate/polymer (dimer),it was washed using deionized water to remove the raffinat acid and was dried by oven vacuum at $60^{\circ} \mathrm{C}$, in the preparation for next adsorption of zinc ions and the capacities of adsorption-desorption of the resin for $\mathrm{Zn}$ (II) ions which were determined by ICP-MS. The recovery of nHAPTCP/PLGA scaffold was used three-seven recycles of adsorption-desorption process and the results indicated that the weight losses in the activity of the nano-composites, for the first seven recycles the composition will be negligible.

\section{Results and Discussion}

Characterization of Poly Lactic-co-Glycolic Acid/ $\beta$-Tri Calcium Phosphate

Study the FT-IR spectrum of $\beta$-TCP/PLGA before and after $37^{\circ} \mathrm{C}$ incubation was carried out. The absorption bands at maximum values were 1094, 1034,603 and $564 \mathrm{~cm}^{-1}$, from phosphate group [ $23], \beta$-TCP. The approximately band at $3420 \mathrm{~cm}^{-1}$, as the result of $\mathrm{OH}^{-}$-group and $\mathrm{H}^{+}$bonds at 1420 and $631 \mathrm{Cm}^{-1}$ as the result of $\mathrm{OH}$ was attributed to the bending vibrations of $\mathrm{OH}$-group. The approximately band at $1600 \mathrm{Cm}^{-1}$ was observed for $\mathrm{H}-\mathrm{O}-\mathrm{H}$, for characterization absorption bands at 1750 to $2926 \mathrm{Cm}^{-1}$., stretching vibrations of the $\mathrm{C}=\mathrm{O}$ and $\mathrm{C}-\mathrm{H}$ group of PLGA, respectively absorption[ 23] at $1457 \mathrm{Cm}^{-1} \cdot \mathrm{CH}_{2}$-group as originates from the bending vibrations $875-860$ $\mathrm{Cm}^{-1}$., alternative OH-group in C-P group [24-26]. Fig. (1b) shows ( as supplementary material) FTIR spectrum spectroscopy of $\beta$-TCP/PLGA before and after $37^{\circ} \mathrm{C}$ incubation.

\section{Scanning electron microscope analysis}

The SEM micrographs of the synthesized HAp Nano powder from animal scale and $\beta$-TCP sources $\left(\beta-\mathrm{Ca}_{3}\left(\mathrm{PO}_{4}\right)_{2}\right)$ is a synthetic, completely inorganic compound, this was shownfrom Figures $2 \mathrm{a}$ and $2 \mathrm{~b}$ (supplementary materials). 


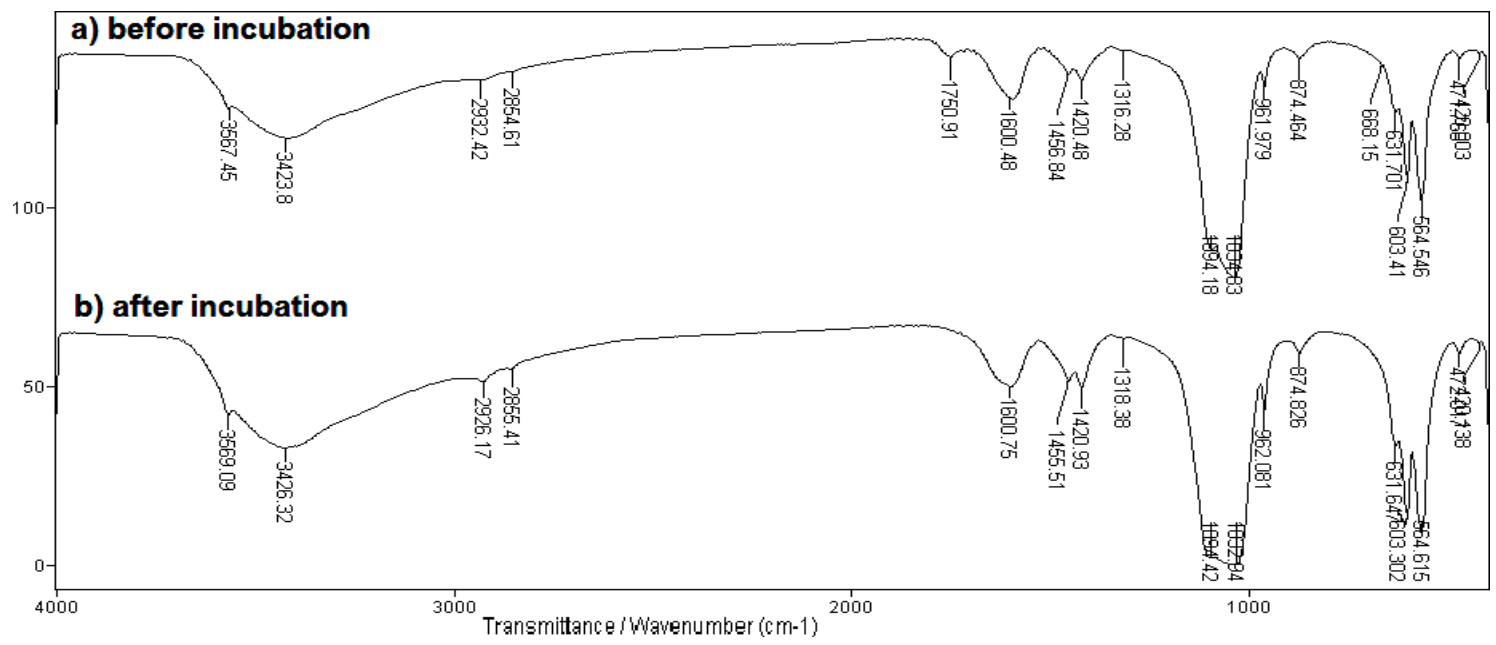

Fig. (1b): FT-IR spectrum spectroscopy of $\beta$-TCP/PLGA before and after $37^{\circ} \mathrm{C}$.

SEM investigation was conducted for the nanocomposites/polymer before and after removal of zinc ions. Scanning electron microscope analysis of nano-composites before and after addition of PLGA are shown in Figs. $(2 \mathrm{a}, 2 \mathrm{~b})$ where the small particles from HAP/ $\beta$-TCP are revealed in Fig. (2a) which shows the diffused resin without regularity and therefore it is difficult to determine of crystalline composite [27] Fig. (2b) shows the combination of product $2 \mathrm{a}$, with a numerous pores and relatively decreased size which leads to an increase in the contact areas and activated pores for PLGA.

\section{Study of Adsorption process}

The amount of metal ions absorbed from aqueous solution onto PLGA-composites in contact after an appropriate connection reached the balance. The adsorption of $\mathrm{Zn}$ (II) and $\mathrm{Co}$ (II) ions by Poly Lactic-co-Glycolic Acid (PLGA) was found at a period of $90 \mathrm{~min}$ as sufficient to the composites resin saturated with metal ions using different data from uptake experiment and calculating the distribution ratios of the adsorption in Fig. (3): This Figure shows the adsorption of different metal ions as a function of initial concentration and the adsorption of metal ions such as zinc and cobalt by the modification PLGA as a function of their concentrations under room temperature. The percentage of adsorption of metal ions decreased with increasing of metal ions concentration in aqueous solutions. These results indicated that an increase of metal ions concentrations occur due to lower energetic sites $\mathrm{c}$ in aqueous solutions. The maximum percentage of $\mathrm{Zn}$ was $78 \%$ and Co (II) was $65 \%$, these values are satisfactory for artificial bones and low cost as the uptake metal ions that depend on diffusion ions in aqueous solution mechanism of exchanger surface.

The distribution ratio as a function of metal ion concentrations is shown in Fig. (4). It was noticed that the distribution coefficient values $(\mathrm{Kd})$ increase with decreasing metal ions concentrations as a result of the fact that the energetic sites became of a lower contribution with the metal concentration increasing in nitric acid solution.

\section{Modeling of adsorption isotherms}

Equilibrium of adsorption isotherms plays a substantial role in the adsorption systems between solid-liquid phases with increasing concentration reaching equilibrium phase. Figure (5) shows the adsorption isotherms plotted between amount of adsorbed versus the amount of metal ions in equilibrium $\mathrm{C}_{0}$ as initial concentration of metal ions such as zinc and cobalt where the amount of Zinc ions sorbed is greater than the $\mathrm{Co}(\mathrm{II})$ and sorbent ions at $0.82 \mathrm{mmol} / \mathrm{g}$ for zinc, $0.3 \mathrm{mmol} / \mathrm{g}$ for cobalt respectively as a result of various sorption capacity .The differential sorption between two ions is attributed to the ionic radii for $\mathrm{Zn}(\mathrm{II})>\mathrm{Co}(\mathrm{II})$. Generally: adsorption experimental measurements and Langmuir and Freundlich models isotherm, can be applied for contaminant sorbent investigations.

Figs. $(6,7)$. reveal the sorption data of correlation linear from Langmuir isotherm according to equation (3):

$$
\frac{C_{f}}{C_{a d s}}=\frac{1}{Q_{b}}+\frac{C_{f}}{Q}
$$




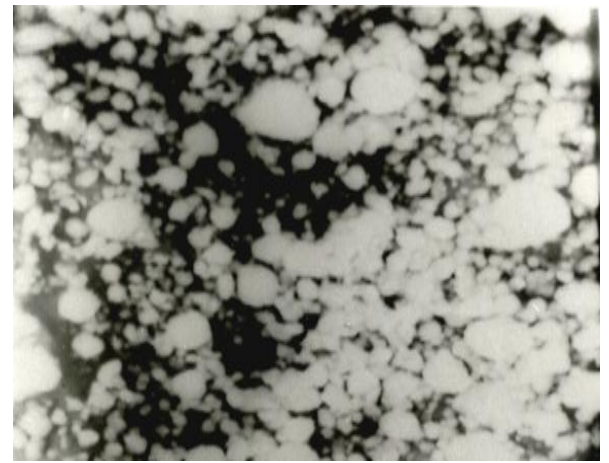

Fig. (2a): SEM for HAP/ $\beta$-TCP-composites without polymer Before PLGA

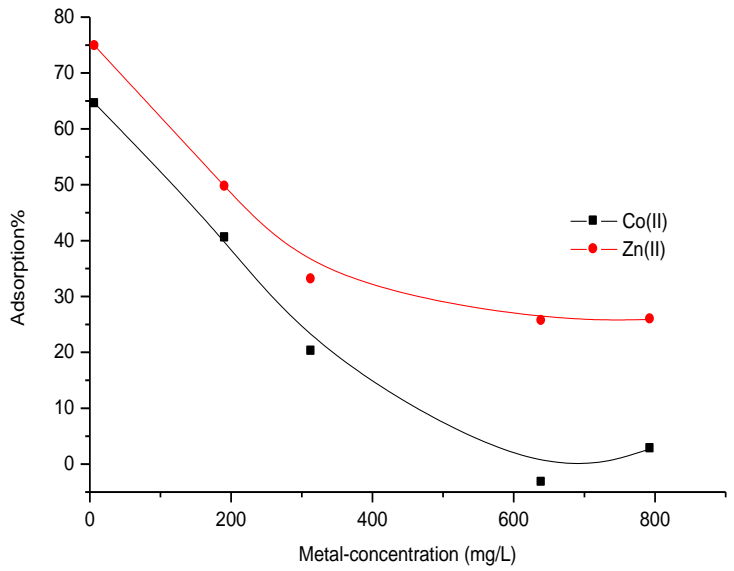

Fig. (3): Effect of the Adsorption on the metal ion concentrations

$\mathrm{C}_{\mathrm{f}}$ is equilibrium concentration of $\mathrm{Zn}(\mathrm{II})$ and $\mathrm{Co}$ (II) in aqueous solution, $\mathrm{C}_{\mathrm{ads}}$ is number of metal adsorbed onto PLGA-composites, $\mathrm{Q}$ and $\mathrm{b}$ as Langmuir constants are related to capacity and energy sorption respectively. The maximum sorption capacity Q is a monolayer a perfusion of PLGA-composites-metal ions Zn (II) \& Co (II) or sorbate-sorbent and b enthalpy of sorption at various temperature, from Freundlich isotherm linearized

$$
\log C_{a d s}=\log K+\frac{1}{n} \log C_{e}
$$

$\mathrm{C}_{\mathrm{e}}$ is equilibrium, concentration in $\mathrm{mg} / \mathrm{l}$ for metal ions, $\mathrm{Q}$ and $\mathrm{b}$ are Langmuir isotherm constants, $\mathrm{K}$ and $\mathrm{n}$ are Freundlich isotherm constants; $\mathrm{R}$ is correlation coefficient for linear regression on the results and represented in Table (1). Freundlich's isotherm equation for zinc and cobalt metals is the constant $\mathbf{K}$ depending on the temperature and $\mathbf{n}$ is a distinguishing constant for the adsorption system

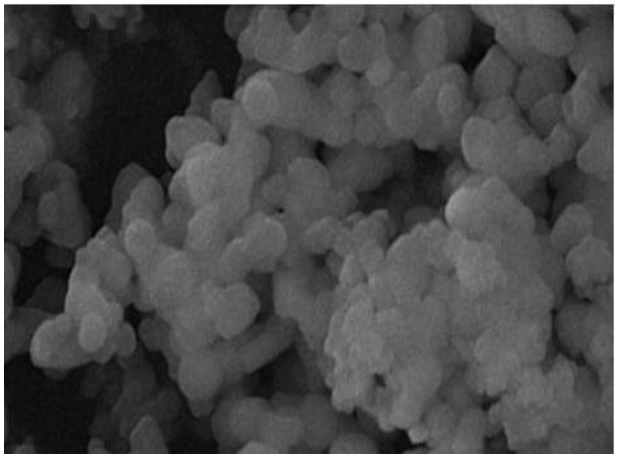

Fig. (2b): SEM for HAP/ $/$-TCP after added PLGA

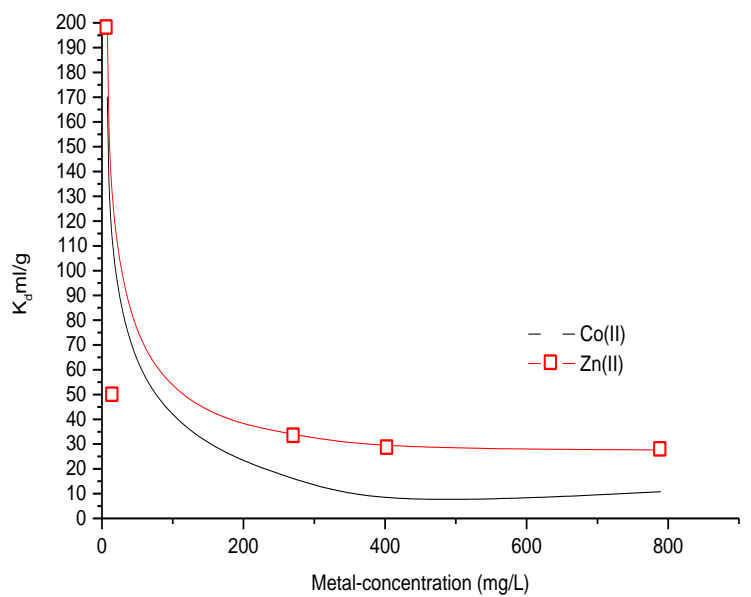

Fig. (4): Effect of $K_{d}$ of $Z n$ (II)/ Co (II) concentrations

under conditions. $\mathrm{n}$ value $(>1)$ shows the best adsorption and the comparison of correlation coefficients for two models. The experimental data correlated the Langmuir model is the better than Freundlich isotherm $(28,29)$.

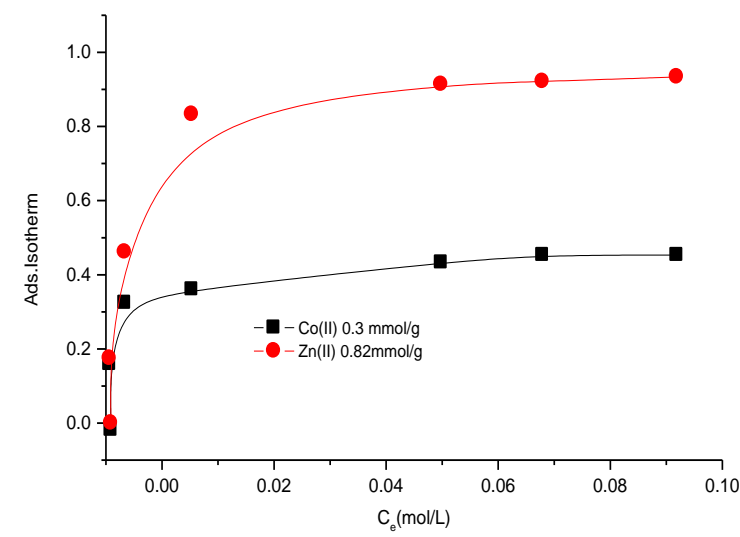

Fig. (5): Isotherm constants for adsorbents at different initial concentrations for $\mathrm{Co}$ (II) and $\mathrm{Zn}$ (II) metal ions 


\section{Study of the recycling and recovery adsorbent} It has been proven from Research and Development (R\&D) in the field of engineering techniques to recycle some compounds that these compounds need high temperature to break resin sufficiently and get the metal that can be used again. For example, zinc has been processed for recycling to improve surface quality conditions and recoverable organic product value while providing a significant portion of energy and chemical reagents and cost -effective strategies. The recycling and recovery of the nHAP/ $\beta T C P / P L G A$ composites scaffold would decrease the processing costs and recovery may occur after $\mathrm{Zn}$ (II) ions extraction from aqueous solutions. There is an ability to reuse the composites scaffold. The application of recycling nanoparticles plays an influential role in the reuse of scaffold resins tested through seven absorption / capacity absorption cycles. Table (2): shows the influence of the recycles number of zinc ions solution. The nano-composites could be recycled above 6 times for recycle of zinc, and the adsorption capacity from 1 st -7 st 30.78 and 18.67 from adsorption- desorption respectively(Table 2)Therefore, the results, indicated that the nanocomposites can be used as adsorbent.

Table (1): Linear forms of the Langmuir and Freundlich isotherm models

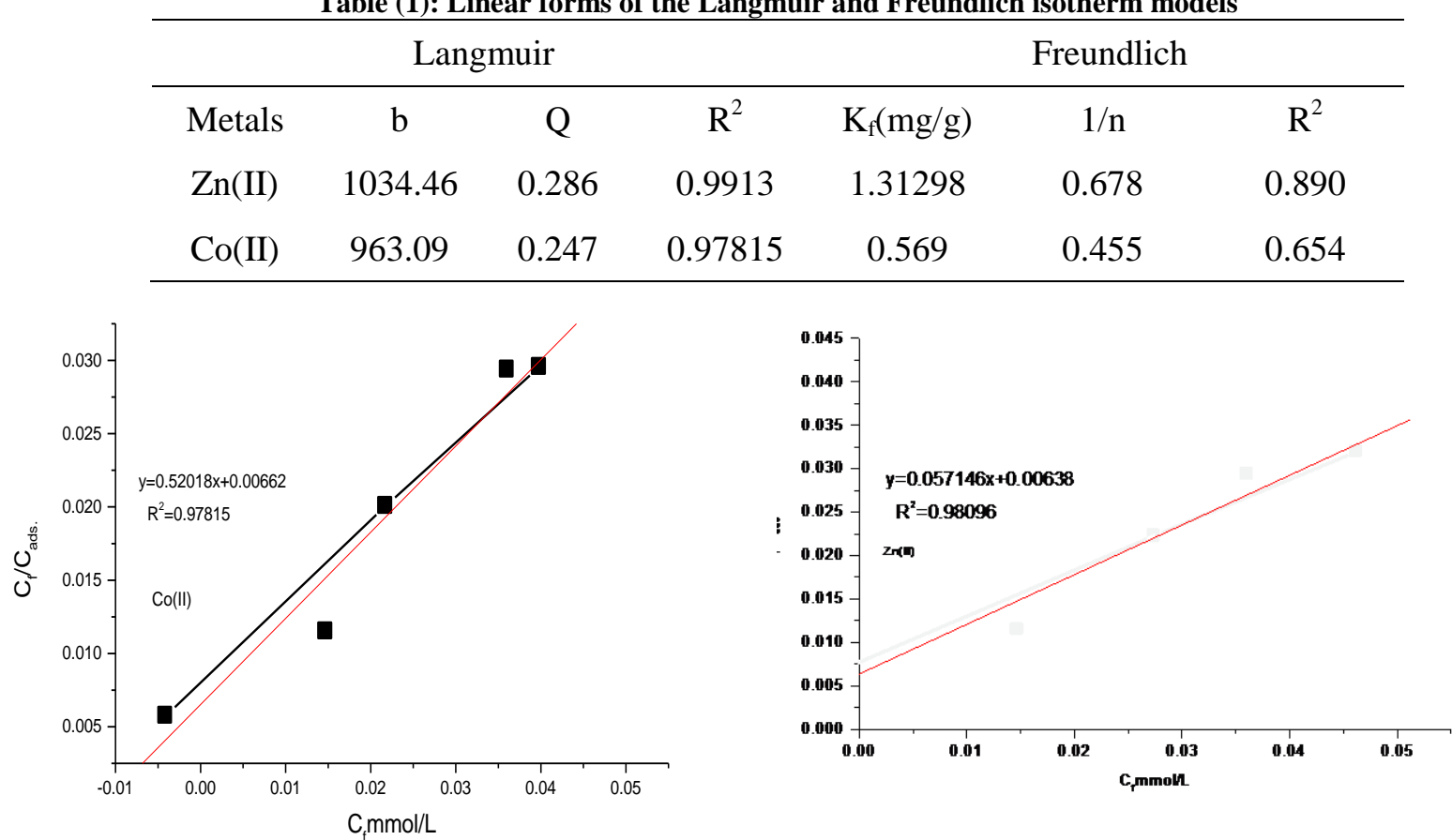

Fig. (7): Non-linear fitting of Langmuir, isotherm model for the adsorbents of $\mathrm{Co}$ (II) ion

Fig. (6): Non-linear fitting of Langmuir, isotherm model for the adsorbents of $\mathrm{Zn}$ (II) ion.

Table (2): Recovery and Reuse Adsorbent

\begin{tabular}{ccccccccc}
\hline & $\begin{array}{c}\text { Ads. } \\
\text { Capacity }\end{array}$ & 1 st & 2 st & 3 st & 4 st & 5 st & 6 st & 7 st \\
\hline Final Adsorption & 568.792 & 233.045 & 133.67 & 74.002 & 45.783 & 22.132 & 10.798 & 2.339 \\
$\begin{array}{c}\text { Capacity } \\
\text { Initial Adsorption } \\
\text { Capacity }\end{array}$ & 48.832 & 29.65 & 18.62 & 11.78 & 8.986 & 4.675 & 2.879 & 0.000 \\
\hline
\end{tabular}




\section{Conclusions}

This study proved the possibility of the use of polymerization opening ring (POR) for the treatment of metal ions such as zinc and cobalt ions from aqueous medium. Poly Lactic-coGlycolic Acid (PLGA) carboxylic groups as a functional to polymer chains, represents the degree of Carboxylic acid and cation exchanges capacity was $0.63 \mathrm{meq} / 100 \mathrm{~g}$ of hydroxyapatite with $\beta$-Tricalcium phosphate. Studying the adsorption isotherms of PLGA-composites resin with artificial, wastewater containing zinc and cobalt ions specified, cation exchanges capacity of PLGA were 30 and $83 \mathrm{meq} / 100 \mathrm{~g}$ for cobalt and zinc ions respectively. For the two different metal ions removal percentage larger than $85 \%$, the adsorption $\%$ as a result was obtained at different concentrations which depicts the pattern of adsorption for Langmuir isotherms. Modification with PLGA show that the cycle's number of adsorptions ranging from 3-6 do not exceed at 7 cycles. Studying the influence of adsorption isotherm for two models and the fitting of cations occur at the Langmuir model shows that it is better than Freundlich model.

\section{References}

1. Dastgheib S.A, Rockstraw DA and Pecan Shell. Activated Carbon: Synthesis, Characterization, and Application for the Removal of Copper from Aqueous Solution. Carbon .J.;39(1) 2001.

2. Toles CA, Marshall WE, Johns M.M. Phosphoric Acid Activation of Nutshells for Metals and Organic Remediation: Process Optimization; Chem. Technol. Biotechnol.J: 72(3) 1998.

3. Toles CA, Marshall WE, Johns MM. Granular Activated Carbons from Nutshells for the Uptake of Metals and Organic Compounds. Carbon.J.35( 1997)..

4. Alfarra A, Frackowiak E and Béguin F.; The HSAB Concept as a Means to Interpret the Adsorption of Metal Ions onto Activated Carbons. Appl. Surf. Sci.J.228 (2004).

5. Ahrland S, Chatt J, Davies NR.; The Relative Affinities of Ligand Atoms for Acceptor Molecules and Ions. Q. Rev. Chem. Soc.J.12 (1958).

6. Duffus JH.; Heavy Metals; IUPAC Technical Report; Pure Appl. Chem.J.74 (2002).
7. Periasam K, Srinivasan K and Murugan PR.; Studies on chromium(VI) removal by activated round-nut husk carbon. Indian J. Environ. Health .J.33 (1991).

8. Parfitt AM, Mathews AR,Villanueva M, Kleerekoper M, Frame B and Rao DS.; Relationship between surface, volume and thickness of trabecular bone in aging and in osteoporosis. J. Clin. Inv.72 (1983).

9. Tewari PH.; Adsorption from Aqueous Solution, 1st ed.; Plenum Press: New York, NY, USA, 1981.

10. Ekpete OA and Horsfall H.J.; Preparation and characterization of activated carbon derived from fluted pumpkin stem waste. Res. J. Chem. Sci. 1(2011).

11. Puzii A.M, Stavitskaya S S, Poddubnaya O I, Vikarchuk VM and Tsyba, N.N.; Structural and adsorption properties of active carbon from coconut shells modified with phosphorus heteroatoms. J. Therm. Analy. Calo. 124(2016).

12. Reed BE, Matsumoto M.R.; Modeling Surface Acidity of Two Powdered Activated Carbons: Comparison of Diprotic and Monoprotic Surface Representations. Carbon.J.29 (1991).

13. Guo J and Lua AC.; Textural and Chemical Characterizations of Activated Carbon Prepared from Oil-palm Stone with $\mathrm{H} 2 \mathrm{SO} 4$ and $\mathrm{KOH}$ Impregnation. Micro. Meso. Mater.32 (1999).

14. Edris B and Amir,H.; Heavy metals removal from aqueous environments by electrocoagulation process- a systematic review.J. Envir. Heal. Sci. Eng.,74(13) (2015).

15. Nouri L, Ghodbane I, Hamdaoui O, and Chiha M. Batch sorption dynamics and equilibrium for the removal of cadmium ions from aqueous phase using wheat bran. J. Hazard. Mater. 149: 115-125 (2007).

16. Ehsan N, Ahmed M and Mika S.;(2018). Nanoadsorbents based on conducting polymer nanocomposites with main focus on polyaniline and its derivatives for removal of heavy metal ions/dyes: A review.J. Env. Res., 162(2018).

17. Stefan Flauder, Uwe Gbureck Frank A.Müller,.Structure and mechanical properties of $\beta$-TCP scaffolds prepared by ice-templating with preset ice front velocities Acta Biomaterial, Volume 10, Issue 12, December 2014, Pages 5148-5155. 
18. Foo, K.Y.; Hameed, B.H. Insights into the modeling of adsorption isotherm systems.Chem. Eng. J.2010, 156, 2-10.

19. Kinniburgh, D.G. General purpose adsorption isotherms. Environ. Sci. Technol. 1986, 20, 895-904. 18.

20. Ho, Y.S. Isotherms for the sorption of lead onto peat: Comparison of linear and non-linear methods. Pol. J. Environ. Stud. 2005, 15, 8186.

21. Rodrigues, L.; Maschio, L.; Coppio, L.; Thim, G.; da Silva, M. Adsorption of phosphate from aqueous solution by hydrous zirconium oxide. Environ. Technol. 2012, 33, 1345-1351.

22. Mao, Y.; Pham, A.N.; Xin, Y.; Waite, T.D. Effects of $\mathrm{pH}$, floc age and organic compounds on the removal of phosphate by prepolymerized hydrous ferric oxides. Sep. Purif. Technol. 2012, 91, 38-45.

23. Huang, W.; Li, D.; Zhu, Y.; Xu, K.; Li, J.; Han, B.; Zhang, Y. Fabrication of $\mathrm{Fe}$ coordinated diamino-functionalized SBA-15 with hierarchical porosity for phosphate removal. Mater. Lett. 2013, 99, 154-157.

24. Huang, W.; Li, D.; Yang, J.; Liu, Z.; Zhu, Y.; Tao, Q.; Xu, K.; Li, J.; Zhang, Y. One-pot synthesis of $\mathrm{Fe}(\mathrm{III})$-coordinated diamino- functionalized mesoporous silica: Effect of functionalization degrees on structures and phosphate adsorption. Microporous Mesoporous Mater. 2013, 170, 200-210.

25. S. Mohan, and J. Karthikeyan. Removal of lignin and tannin color from aqueous solution by adsorption on to activated carbon solution by adsorption on to activated charcoal", Environ. Pollut. 97, (1997) pp.183-187

26. Z.Mitic,S.Stojanovic,S.Najman,M.Cakic,N.Ign jatovic,D.Uskokovic,A.Stolic and M.Trajanovic., FTIR and SEM-EDX spectroscopic characterization of Biomaterial Calcium phosphate/poly-(DL-Lactide-CoGlycolide).J.physical chemistry 2014,518-521.

27. N.El-said, M.MS. Ali and Mostafa M.Hamd.; Nanoapatite for Nanotechnology: part (III) A novel process for the fabrication and Improvement of nanoporous apatites from synthetic hydroxyapatite (HAp) in vitro activated carbon, IOSR Journal of Applied Chemistry (IOSR-JAC),7(1)2014

28. Langmuir I. (1918). The adsorption of gases on plane surfaces of glass, mica and platinum, Journal of the Amer.Chem. Soc. 40(1918).

29. Freundlich HMF.; . Over the adsorption in solution, J.Phys. Chem., 57(1906). 